\title{
Viewpoint
}

\section{Corticosteroids in rheumatoid arthritis: Is a trial of their 'disease modifying' potential feasible?}

\author{
MARGARET A BYRON ${ }^{1}$ AND JOHN R KIRWAN
}

From the ${ }^{1}$ Department of Rheumatology, Nuffield Orthopaedic Centre, Headington, Oxford and the Fibrinolysis Research Group, Nuffield Department of Obstetrics and Gynaecology, John Radcliffe Infirmary, Oxford, and the ${ }^{2}$ Bone and Joint Research Unit, The London Hospital Medical College, Turner Street, London

After three decades of experience the use of corticosteroids to treat rheumatoid arthritis (RA) remains a matter of personal taste and generates much debate. Although their role in life threatening complications is apparently acceptable, one standard text ${ }^{1}$ suggests that less than $5 \%$ of patients with predominantly articular disease will require them, and in a recent survey British rheumatologists reported using corticosteroids only 'occasionally' or 'very infrequently' ${ }^{2}$ However, when making clinical decisions a physician's opinion does not necessarily reflect his clinical practice. ${ }^{3}$ Recent studies have found that 24 of 100 consecutive RA patients seen at one British hospital were taking a mean daily dose of $5.6 \mathrm{mg}$ of prednisolone ${ }^{2}$ and that $15 \%$ of outpatients seen at a Dutch clinic were also receiving steroid treatment. ${ }^{4}$

EFFECT OF STEROIDS

Although corticosteroids are very effective in diminishing pain, swelling, and stiffness, to maintain

Accepted for publication 12 September 1985.

Correspondence to Dr Margaret A Byron, clo Maternity Department, Level 3, John Radcliffe Hospital, Headington, Oxford OX3 9DU. suppression of inflammation the dose must be increased to levels too toxic for long term administration. ${ }^{56}$ Yet even at lower doses there are marked effects on the immune system. ${ }^{7}$ Might we not expect a 'disease modifying' action (like gold and penicillamine) even when an anti-inflammatory effect, like that of aspirin, is no longer present?

Results of some studies of the effects of corticosteroids in RA are difficult to interpret in this respect because they are poorly controlled, ${ }^{89}$ too short term, ${ }^{10}$ or use large doses. ${ }^{9}$ However, tantalising evidence of a possible disease modifying effect derives from the combined MRC and Nuffield Foundation study of the $1950 \mathrm{~s}^{56}$ and a follow up study by West. ${ }^{11}$ Eighty four patients were randomly allocated to receive either analgesics or (effectively) analgesics plus prednisolone, initially at a dose of 20 $\mathrm{mg}$ daily but subsequently tailored to each patient so that the mean daily dose at two years was $10 \mathrm{mg}$. Radiological progression was much less in the steroid treated group (Table 1). This was clearly significant even when a more stringent statistical analysis was applied than that originally employed.

These overall assessments may, however, conceal the answer to arguably the most important

Table 1 Evaluation of hand radiographs in the combined MRC and Nuffield Foundation trial ${ }^{4}$

\begin{tabular}{|c|c|c|c|c|c|c|c|}
\hline \multirow[t]{2}{*}{ Therapy } & \multirow[t]{2}{*}{ Time } & \multicolumn{5}{|c|}{ Erosion grade } & \multirow{2}{*}{$\begin{array}{l}\text { Total number } \\
\text { of patients } \\
\text { in trial }\end{array}$} \\
\hline & & 0 & 1 & 2 & 3 & 4 & \\
\hline Analgesics & $\begin{array}{l}\text { Initially } \\
{ }^{*} \text { At two years }\end{array}$ & $\begin{array}{r}13 \\
4\end{array}$ & $\begin{array}{l}5 \\
1\end{array}$ & $\begin{array}{l}11 \\
13\end{array}$ & $\begin{array}{r}5 \\
11\end{array}$ & $\begin{array}{l}1 \\
6\end{array}$ & $\begin{array}{l}39 \\
36\end{array}$ \\
\hline $\begin{array}{l}\text { Prednisolone } \\
\text { and analgesics }\end{array}$ & $\begin{array}{l}\text { Initially } \\
{ }^{*} \text { At two years }\end{array}$ & $\begin{array}{r}15 \\
9\end{array}$ & $\begin{array}{l}8 \\
8\end{array}$ & $\begin{array}{l}13 \\
16\end{array}$ & $\begin{array}{l}4 \\
4\end{array}$ & $\begin{array}{l}1 \\
4\end{array}$ & $\begin{array}{l}45 \\
41\end{array}$ \\
\hline
\end{tabular}

$\chi^{*}=51, \mathrm{p}<0 \cdot 01$. 
Table 2 Follow up study of MRC and Nuffield Foundation trial by West ${ }^{\prime \prime}$

\begin{tabular}{llll}
\hline Therapy & $\begin{array}{l}\text { Number of } \\
\text { patients }\end{array}$ & $\begin{array}{l}\text { Duration of } \\
\text { follow up } \\
\text { (years) }\end{array}$ & $\begin{array}{l}\text { Number } \\
\text { developing } \\
\text { new erosions }\end{array}$ \\
\hline $\begin{array}{l}\text { Analgesics } \\
\text { Prednisolone } \\
\text { and analgesics }\end{array}$ & 34 & 5 & $32(94 \%)$ \\
\hline
\end{tabular}

question-Do corticosteroids prevent the development of new erosions? In a follow up study of 73 of the original patients ${ }^{8}$ only $23 \%$ of those taking prednisolone (mean daily dose $11 \mathrm{mg}$ ) for four years developed new erosions, while $94 \%$ of those receiving analgesics alone (for five years) did so (Table 2).

When the data from the original study ${ }^{56}$ are reviewed and the patients most likely to show evidence of new erosion development (that is, patients with an initial $x$ ray classification of 'none' or 'doubtful' change) are considered it can be seen that most of this deterioration occurred over the first two years; $20 \%$ in the steroid group and $60 \%$ in the analgesic group. Therefore, a two year test of the effects of lower dose steroid treatment should provide clear cut evidence about its ability to prevent the development of erosions in patients with minimal initial $x$ ray changes. If a linear doseresponse relationship is assumed then $7.5 \mathrm{mg}$ prednisolone daily would be expected to reduce the number of patients developing new erosions from $60 \%$ to $33 \%$.

\section{TRIAL DESIG N}

How many patients should be entered in a clinical trial in order to be reasonably sure (with a power of say $90 \%$ ) of identifying such a clinically important advantage of treatment? By referring to published tables $^{12}$ it can be seen that 80 would be required in the test and in the control groups, i.e., 160 patients in all. Some patients would be lost to follow up and a few (probably very few) withdrawn from treatment. A reasonable final estimate would be 180 patients fitting the original trial criteria and having no erosive change. The effects of other 'disease modifying' drugs, such as gold or penicillamine, on radiological progression are small ${ }^{13}$ and would be negligible in a trial this size. It would not be necessary to restrict their use.

\section{F E A S I B I L I T Y}

Would such a trial be feasible? Fifteen rheumatologists recruiting one patient per month would reach

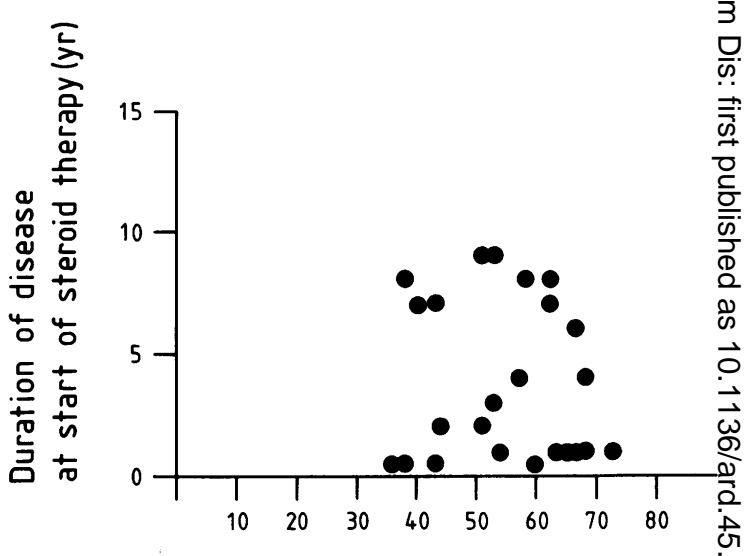

Age when steroids commenced $(\mathrm{yr}) \stackrel{\text { i }}{\stackrel{\text { v }}{v}}$

Fig. 1 Age and duration of disease for 24 patients taking corticosteroids for rheumatoid arthritis.

the target in one year, and the study would be completed in three years. Organisation on this scadec $\overrightarrow{0}$ seems practicable. Could suitable patients, resa tively young and early in the course of their disease, ethically be entered? In current practice mamy? patients are less than 60 years old when steroid treatment is started and have had a short duration of disease, making it likely that they would satisfy the entry criteria. Fig. 1 shows the distribution of age and disease duration at commencement of therapyọ for one group of patients. ${ }^{2}$

\section{Conclusion}

It seems that a trial of low dose corticosteroids for the prevention of erosion development is feasible but should it be performed? The answer depends on whether the result (positive or negative) wouldB influence prescribing and whether a fixed dose of $7 \cdot 50$ $\mathrm{mg}$ prednisolone daily is an acceptable long term? treatment in relation to potential adverse reactions 0 We would be interested in the views of others on both these issues.

\section{References}

1 Dick W C. Drug treatment of rheumatoid arthritis. In: Scott J T, ed. Copeman's textbook of the rheumatic diseases. 5th ed. Edinburgh: Churchill Livingstone, 1978: 404-46.

2 Byron M A. Mowat A G. Corticosteroid prescribing in rheumatoid arthritis-the fiction and the fact. BrJ Rheumato? 1985; 24: 164-6.

3 Friesen W T, Hekster Y A, van de Putte L B A, Gribnau F W J Cross-sectional study of rheumatoid arthritis treatment in university hospital. Ann Rheum Dis 1985; 44: 372-8. 
4 Kirwan J R, Chaput de Saintonge D M, Joyce C R B, Currey H L F. Clinical judgment in rheumatoid arthritis. II. Judging 'current disease activity' in clinical practice. Ann Rheum Dis 1983; 42: 648-51.

5 Joint Committee of the Medical Research Council and the Nuffield Foundation. A comparison of prednisolone with aspirin or other analgesics in the treatment of rheumatoid arthritis. Ann Rheum Dis 1959; 18: 173-87.

6 Joint Committee of the Medical Research Council and the Nuffield Foundation. A comparison of prednisolone with aspirin or other analgesics in the treatment of rheumatoid arthritis. Ann Rheum Dis 1960; 19: 331-7.

7 Fauci A S, Dale D C, Balow J E. Glucocorticosteroid therapy: mechanisms of action and clinical considerations. Ann Intern Med 1976; 84: 304-15.

8 Berntsen C A, Freyberg R H. Rheumatoid patients after 5 or more years of corticosteroid treatment: a comparative analysis of 183 cases. Ann Intern Med 1961; 54: 938-53.

9 Million R, Poole P, Kellgren J H, Jayson M I V. Long term study of management of rheumatoid arthritis. Lancet 1984; i: 812-6.

10 Harris E D, Emkey R D, Nichols J E, Newgerg A. Low dose prednisone therapy in rheumatoid arthritis: a double blind study. J Rheumatol 1983; 10: 713-21.

11 West H F. Rheumatoid arthritis: the relevance of clinical knowledge to research activities. Abstracts of World Medicine 1967; 41: 401-17.

12 Fleiss J L. Statistical methods for rates and proportions. New York: Wiley, 1981.

13 Kirwan J R, Currey H L F. Rheumatoid arthritis-disease modifying antirheumatic drugs. In: Klippel J H. Decker J L, eds. Clinical trials in rheumatic diseases. Eastbourne: Saunders, 1983; Clin Rheum Dis 1983; 9: 581-99. 